\title{
COMPOSIÇÃo QUÍMICA DA PRECIPITAÇÃO ATMOSFÉRICA NO SUL DO BRASIL - ESTUDO PRELIMINAR
}

\author{
Daniela Montanari Migliavacca, Elba Calesso Teixeira* e Andrea Cassia de Melo Machado \\ Fundação Estadual de Proteção Ambiental, Rua Carlos Chagas, 55, 90030-020 Porto Alegre - RS \\ Marçal Rodrigues Pires \\ Pontifícia Universidade Católica do Rio Grande do Sul, Av. Ipiranga, 6500, 90619-900 Porto Alegre - RS
}

Recebido em 16/12/03; aceito em 19/1/05; publicado na web em 13/4/05

\begin{abstract}
CHEMICAL COMPOSITION OF ATMOSPHERIC PRECIPITATION IN SOUTHERN BRAZIL - PRELIMINARY STUDY. The present work is a preliminary study of total and wet precipitation in the Candiota region, RS. The samples were collected from January to June 2001 at four different sites. The following variables were analysed: $\mathrm{pH}$, conductivity, alkalinity, $\mathrm{Cl}^{-}, \mathrm{NO}_{3}^{-}, \mathrm{F}^{-}, \mathrm{SO}_{4}^{2-}$ , $\mathrm{Na}^{+}, \mathrm{K}^{+}, \mathrm{Mg}^{2+}, \mathrm{NH}_{4}^{+}, \mathrm{Ca}^{2+}$ and $\mathrm{Zn}, \mathrm{Cu}, \mathrm{Fe}, \mathrm{Al}, \mathrm{Mn}$. The results showed slightly acidic precipitation and higher concentrations of $\mathrm{NH}_{4}^{+}, \mathrm{Na}^{+}, \mathrm{Cl}^{-}$and $\mathrm{SO}_{4}{ }^{2-}$. Factor analysis applied to the variables studied allowed identifying the major sources. $\mathrm{Na}^{+}, \mathrm{Cl}^{-}$and $\mathrm{Mg}^{2+}$ have their origin in sea salts and $\mathrm{NH}_{4}^{+}, \mathrm{Ca}^{2+}, \mathrm{K}^{+}, \mathrm{SO}_{4}{ }^{2-}$ and $\mathrm{NO}_{3}^{-}$are from local anthropogenic sources.
\end{abstract}

Keywords: atmospheric precipitation; acid precipitation; factor analysis.

\section{INTRODUÇÃO}

O crescimento da industrialização, bem como da população urbana levaram a uma demanda maior de energia provocando, assim, maior emissão de poluentes atmosféricos $\left(\mathrm{SO}_{2}, \mathrm{NOx}, \mathrm{com}-\right.$ postos orgânicos voláteis (VOCs) e aerossóis). A queima de combustíveis fósseis para geração de energia está entre as principais fontes de emissão destes poluentes atmosféricos. Um dos efeitos causados por estas emissões é a precipitação ácida.

Nas últimas décadas, as precipitações ácidas têm sido um problema ambiental sério nos Estados Unidos e na Europa. O aumento das emissões de $\mathrm{SO}_{2}$ proveniente da queima de combustíveis fósseis tem sido responsável pelo decréscimo do $\mathrm{pH}$ das precipitações, com valores entre 4 - 4,5 $5^{1}$ Nos países da América do Sul a questão da precipitação ácida tem sido estudada com menor ênfase existindo, ainda, poucos trabalhos relativos à qualidade da precipitação e seus impactos ambientais.

Embora a precipitação atmosférica natural apresente caráter levemente ácido, devido à presença no ar de ocorrências naturais de enxofre, nitrogênio e $\mathrm{CO}_{2}$, tem apresentado alterações na sua composição química, bem como uma redução significativa dos valores de $\mathrm{pH}$, em alguns locais do mundo ${ }^{2}$.

A precipitação úmida contém diferentes espécies químicas iônicas e não iônicas ${ }^{3}$. As espécies ionizadas desempenham papel importante nos processos de acidificação, além das espécies carbonáticas, destacam-se os cátions e os ânions inorgânicos $\mathrm{Na}^{+}$, $\mathrm{Ca}^{2+}, \mathrm{Mg}^{2+}, \mathrm{K}^{+}, \mathrm{Cl}^{-}, \mathrm{SO}_{4}^{2-}, \mathrm{NH}_{4}^{+}$e $\mathrm{NO}_{3}^{-}$. Outras espécies iônicas também podem estar presentes nas precipitações úmidas, porém em concentrações menores, como os ânions inorgânicos (fluoreto, fosfato) e orgânicos (formiato, acetato e oxalato).

No sul do Brasil, a queima de combustíveis fósseis, principalmente carvão, está entre as fontes industriais que têm provocado alterações da qualidade ambiental em determinadas áreas, como ocorre na região de Candiota, localizada ao sudoeste do estado Rio Grande do Sul.

Estudos na região têm evidenciado emissões atmosféricas ${ }^{4-9}$ devido ao processo de produção de energia termoelétrica, com utilização

*e-mail: gerpro.pesquisa@fepam.rs.gov.br de carvão pulverizado e queimado em caldeiras de geração de vapor. As emissões de $\mathrm{SO}_{2}$ e $\mathrm{NO}_{x}$, provenientes da queima de combustíveis fósseis, podem ser responsáveis pelos indícios de chuva ácida na região e que têm provocado reclamações por parte do governo uruguaio. Desde 1989, Brasil e Uruguai vem tentado encontrar uma forma de avaliar a qualidade do ar, a fim de verificar a possibilidade de existência ou não de chuva ácida na região de Candiota $^{10}$.

Neste contexto, a proposta deste trabalho foi caracterizar a precipitação atmosférica (total e úmida) em quatro pontos de amostragem na região de Candiota, através de parâmetros físicos e químicos: pH, condutividade, alcalinidade, íons majoritários e alguns metais.

\section{ÁREA DE ESTUDO}

A região de Candiota, situada no sudoeste do estado do Rio

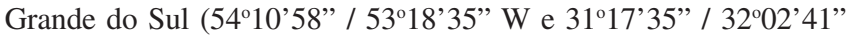
S), distante da capital Porto Alegre cerca de $420 \mathrm{~km}$, abrange total ou parcialmente os municípios de Aceguá, Bagé, Candiota, Herval, Hulha Negra, Pedras Altas e Pinheiro Machado (Figura 1).

Na região estudada situa-se a maior reserva carbonífera brasileira (Jazida Grande Candiota), com aproximadamente 12 bilhões de t, representando cerca de $38 \%$ das reservas de carvão do Brasil, onde aproximadamente $30 \%$ podem ser mineráveis a céu aberto, sendo sua produção destinada para a geração de energia elétrica da Termoelétrica Presidente Médici.

A Usina Termoelétrica Presidente Médici (UPME), operada pela Companhia de Geração Térmica de Energia Elétrica (CGTEE), compõe o maior complexo termoelétrico do Rio Grande do Sul. A curto prazo está previsto o aumento da sua capacidade (mais 350 MW) com a instalação da Usina Candiota III, totalizando 796 MW $^{11}$.

Nesta região está prevista ainda a instalação da Usina Termelétrica Seival, de 500 MW, de responsabilidade da COPELMI - Companhia de Pesquisa e Lavra Mineral ${ }^{12}$. Esta Companhia, juntamente com a Companhia Riograndense de Mineração (CRM), detém as concessões de lavra de carvão mineral na região deste estudo.

Outra atividade econômica importante na região são as indústrias cimenteiras, Companhia de Cimento do Brasil e Cimento Rio Branco, que desde o final da década de 80 exploram as jazidas de 


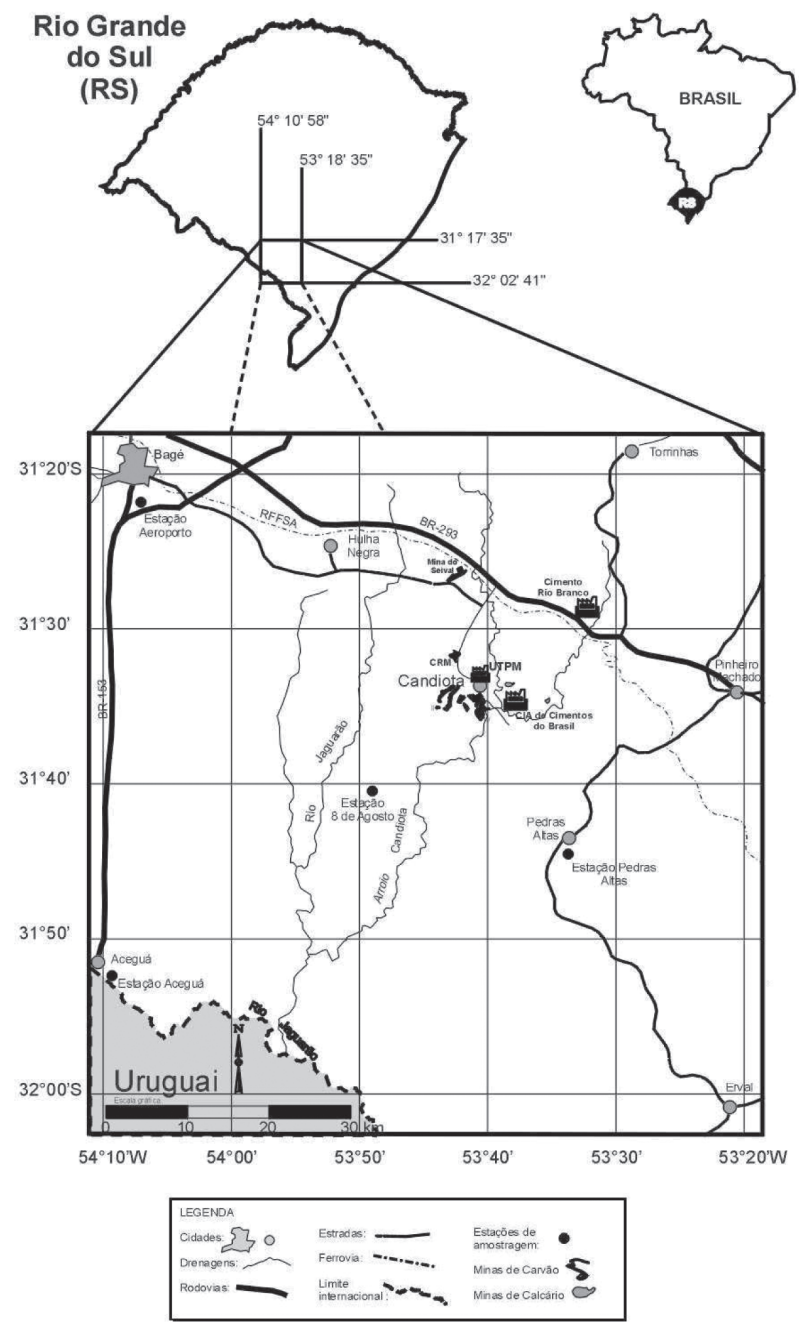

Figura 1. Mapa de localização da Região de Candiota

mármore calcítico. Estas indústrias utilizam como insumos à fabricação do cimento as cinzas geradas no processo de combustão do carvão mineral e as cascas de arroz, importante produto cultivado na própria região. As taxas de emissão de material particulado e $\mathrm{SO}_{2}$ são de 2,5 e $0,21 \mathrm{~g} \mathrm{~s}^{-1}$, respectivamente ${ }^{13}$.

Esta região insere-se no tipo climático Cfa (clima subtropical com precipitações durante todo o ano, segundo a classificação de Von Koepen), com uma precipitação total média anual registrada entre 1961 e 1990 de 1.465 mm, bem distribuída durante o ano, e temperatura média anual de $18{ }^{\circ} \mathrm{C}$, conforme as normais climatológicas obtidas pela estação meteorológica de Bagé. As temperaturas mínimas ocorrem no inverno, nos meses de junho e julho, e as máximas no verão, de dezembro a fevereiro ${ }^{14}$.

\section{PARTE EXPERIMENTAL}

\section{Locais de amostragem}

A escolha dos locais de amostragem de precipitação atmosférica foi realizada com auxílio de cartas topográficas 1:50.000 e trabalho de campo, bem como com o auxílio de GPS ("Global Positionning Systems").

Alguns critérios foram seguidos para a localização das estações de amostragens conforme Normas ASTM $^{15}$, dentre as quais citam-se: distância das fontes poluidoras, condições logísticas (segurança, acesso, fornecimento de energia elétrica), direção predominante do vento e distância de obstáculos que possam interferir na amostragem ( 2 vezes a altura de obstáculos).

Desta forma, 4 locais em um raio de aproximadamente $50 \mathrm{~km}$ da principal fonte emissora (UPME) foram selecionados (Figura 1). Características das estações de amostragens, distâncias em relação a principal fonte emissora (UPME) e tipos de amostradores utilizados em cada estação de amostragem são apresentadas na Tabela 1.

\section{Amostradores de precipitação atmosférica}

Foram utilizados dois tipos de amostradores, um para precipitação total (em todas as estações de amostragens) e outro, de precipitação apenas úmida (localizados nas estações 8 de Agosto e Aceguá). $\mathrm{O}$ amostrador de precipitação total consistiu de um funil de polietileno, com $21,5 \mathrm{~cm}$ de diâmetro, acoplado a um frasco coletor de $5 \mathrm{~L}$ do mesmo material, ambos suportados por estrutura metálica de $1,50 \mathrm{~m}$, ficando a aproximadamente $2 \mathrm{~m}$ do solo. $\mathrm{O}$ funil foi recoberto com tela de nylon para impedir a contaminação das amostras por agentes externos, tais como folhas e insetos.

O amostrador de precipitação apenas úmida, adaptado de Fornaro $^{16}$, é constituído de uma caixa metálica de proteção e um frasco coletor de polietileno, com capacidade de $5 \mathrm{~L}$, acoplada a um funil de acrílico com tampa do mesmo material, cuja tampa abre-se apenas na presença de certa quantidade de precipitação, fechando-se após o término da mesma.

Os procedimentos de limpeza e estocagem dos frascos coletores das amostras de precipitação foram realizadas com água Tipo I (Milli-Q- Millipore) através de várias lavagens (2 ou 3 vezes) e estocados com a mesma, no mínimo por $24 \mathrm{~h}$, cuja condutividade não deveria ser $>2 \mu \mathrm{S} \mathrm{cm} \mathrm{cm}^{-1}$.

Tabela 1. Localização e descrição das estações de amostragem de precipitação atmosférica na região de Candiota, RS

\begin{tabular}{ccccc}
\hline $\begin{array}{c}\text { Estação de } \\
\text { Amostragem }\end{array}$ & $\begin{array}{c}\text { Coordenadas } \\
\text { Geográficas }\end{array}$ & $\begin{array}{c}\text { Distância da } \\
\text { UPME }\end{array}$ & Amostradores & Justificativa \\
\hline Aceguá & $\begin{array}{c}31^{\circ} 52,52^{\prime} \mathrm{S} \\
54^{\circ} 08,81^{\prime} \mathrm{W}\end{array}$ & $57 \mathrm{~km}$ a Sudoeste & Total e Úmido & Fronteira Brasil-Uruguai \\
& $31^{\circ} 40,31^{\prime} \mathrm{S}$ & $18 \mathrm{~km}$ a Sudoeste & Total e Úmido & $\begin{array}{c}\text { Situado na direção predominante do vento } \\
\text { da região, nordeste }\end{array}$ \\
\hline 8 de Agosto & $53^{\circ} 49,74^{\prime} \mathrm{W}$ & & Parâmetros meteorológicos de superfície \\
& $31^{\circ} 23,86^{\prime} \mathrm{S}$ & $44 \mathrm{~km}$ a Noroeste & Total & Altitude máxima 500 m (Serra do Veleda) \\
\hline Aeroporto de Bagé & $54^{\circ} 07,10^{\prime} \mathrm{W}$ & & Total & \\
\hline Pedras Altas & $31^{\circ} 43,94^{\prime} \mathrm{S}$ & $20 \mathrm{~km}$ a Sudeste & & \\
\hline
\end{tabular}




\section{Freqüência e preparação das amostras}

A frequiência de amostragem ao longo do trabalho foi por evento chuvoso (com a retirada do frasco coletor no máximo $12 \mathrm{~h}$ após o evento), com as amostras sendo separadas em várias alíquotas, de acordo com as técnicas analíticas aplicadas. As alíquotas destinadas à análise de $\mathrm{pH}$ e condutividade foram armazenadas sob refrigeração a $4{ }^{\circ} \mathrm{C}$. O período de coleta foi de janeiro a junho/2001.

Duas alíquotas foram filtradas em membrana éster celulose com 0,22 $\mu \mathrm{m}$ de poro (Millipore): 1) para determinação de ânions e cátions, cujas amostras foram preservadas com clorofórmio e 2) para determinação de alguns metais sendo preservadas com $\mathrm{HNO}_{3}$ (Merck suprapur) até $\mathrm{pH}<2,0$. Ambas foram estocadas a $4{ }^{\circ} \mathrm{C}$ para posterior realização das análises químicas.

\section{Análise química}

\section{$p H$, condutividade e alcalinidade}

Medidas de $\mathrm{pH}$ e condutividade foram realizadas in situ em amostras não filtradas. $\mathrm{O} \mathrm{pH}$ foi medido em pHmetro (Mettler Toledo M 90, precisão $\pm 0,01$ ), calibrado com soluções tampão (Merck) de pH 4,02 e 6,99. As medidas de condutividade foram realizadas em condutivímetro (Orion Modelo 105 Aplus, precisão $\pm 0,01$ ) calibrado com solução padrão $1,0 \times 10^{-2} \mathrm{~mol} \mathrm{~L}^{-1}$ de $\mathrm{KCl}$.

Em laboratório, foi medido o volume das amostras e confirmaram-se os valores de $\mathrm{pH}$ e condutividade em alíquota não filtrada. Estas análises foram realizadas em amostras recém chegadas ao laboratório, com pHmetro digital (Digimed DM-20, precisão $\pm 0,01$ ), calibrado com soluções tampão (Merck) de pH 4,02 e 6,99 a $25^{\circ} \mathrm{C}$. As análises de condutividade, em laboratório, foram realizadas utilizando-se condutivímetro (Digimed DM-31, precisão $\pm 0,01$ ) calibrado com solução padrão de $1,0 \times 10^{-3} \mathrm{~mol} \mathrm{~L}^{-1}$ de $\mathrm{KCl}$ com condutividade de $147 \mu \mathrm{S} \mathrm{cm} \mathrm{c}^{-1}$ a $25{ }^{\circ} \mathrm{C}$.

Para cálculo do balanço iônico foram utilizados os valores de pH e condutividade medidos no laboratório, devido à maior confiabilidade do analista, do equipamento e condições mais padronizadas que no campo. Os resultados dos valores de $\mathrm{pH}$ e condutividade medidos in situ e em laboratório apresentaram uma boa correlação ( $\mathrm{pH} \mathrm{r}=0,60, \mathrm{p}=0,00$; condutividade $\mathrm{r}=0,95, \mathrm{p}=$ $0,00)$, não mostrando diferenças significativas no conjunto destes dados.

As concentrações de $\mathrm{H}^{+}$foram calculadas a partir dos valores de $\mathrm{pH}$, e o $\mathrm{pH}$ MPV (média ponderada pelo volume) foi calculado a partir dos valores das concentrações médias ponderadas pelo volume de $\mathrm{H}^{+}$para cada evento de precipitação.

Para determinação da alcalinidade através do método potenciométrico, conforme Norma APHA ${ }^{18}$, foram utilizadas alíquotas de aproximadamente $300 \mathrm{~mL}$, sendo as determinações realizadas em triplicatas.

\section{Cátions e ânions}

As análises de cátions e ânions nas amostras de precipitação total e apenas úmida foram realizadas por cromatografia iônica, utilizando-se equipamento Dionex (modelo DX 500 com detector de condutividade elétrica e sistema de supressão auto regenerativa). Para os ânions $\left(\mathrm{Cl}^{-}, \mathrm{NO}_{3}^{-}, \mathrm{SO}_{4}^{2-}\right.$ e $\left.\mathrm{F}^{-}\right)$utilizou-se coluna AS4A-SC com eluente de $\mathrm{NaHCO}_{3}$ 1,7 mmol L-1/Na $\mathrm{CO}_{3} 1,8 \mathrm{mmol} \mathrm{L}{ }^{-1}$ e vazão de $2 \mathrm{~mL} \mathrm{~min}{ }^{-1}$. Para análise de cátions $\left(\mathrm{Na}^{+}, \mathrm{Ca}^{2+}, \mathrm{Mg}^{2+}, \mathrm{K}^{+} \mathrm{e}\right.$ $\mathrm{NH}_{4}^{+}$), com coluna catiônica CS12A, utilizou-se como eluente solução de $\mathrm{H}_{2} \mathrm{SO}_{4} 21,7 \mathrm{mmol} \mathrm{L}^{-1}$ com vazão de $1,5 \mathrm{~mL} \mathrm{~min}^{-1}$. As condições cromatográficas e a otimização dos métodos analíticos utilizados encontram-se descritas no trabalho de Barrionuevo ${ }^{19}$. Os limites de detecção foram: $1 \times 10^{-2} \mu \mathrm{eq} \mathrm{L}^{-1}$ para $\mathrm{NH}_{4}^{+}, \mathrm{Mg}^{2+}, \mathrm{Na}^{+}, \mathrm{K}^{+}$;
$3 \times 10^{-2}$ eq $\mathrm{L}^{-1}$ para $\mathrm{F}^{-}$e $\mathrm{NO}_{3}^{-} ; 1 \times 10^{-5}$ para $\mathrm{Ca}^{2+} ; 3 \times 10^{-4} \mu$ eq $\mathrm{L}^{-1}$ para $\mathrm{Cl}^{-}$e $5 \times 10^{-2} \mu$ eq $\mathrm{L}^{-1}$ para $\mathrm{SO}_{4}{ }^{2-}$.

Os critérios de controle de qualidade utilizados no presente trabalho foram o balanço iônico e a comparação da condutividade medida e calculada ${ }^{20}$. De forma geral, o balanço iônico foi satisfatório para as amostras estudadas, onde $21 \%$ dos eventos estudados apresentaram uma variação do balanço iônico maior que $25 \%$, que corresponde a amostras com força iônica maior que $100 \mu \mathrm{eq} \mathrm{L}^{-121}$, seguindo este critério as amostras foram rejeitadas. Alguns fatores podem estar relacionados a esta variação do balanço iônico, tais como exposição do amostrador de precipitação total a variações de temperatura, tempo de amostragem e perdas dos compostos instáveis como ácidos orgânicos.

O somatório de ânions e cátions mostrou uma correlação significativa $(\mathrm{r}=0,78, \mathrm{p}=0,00)$, revelando que os principais íons foram determinados nas amostras de precipitação atmosféricas (Figura 2).

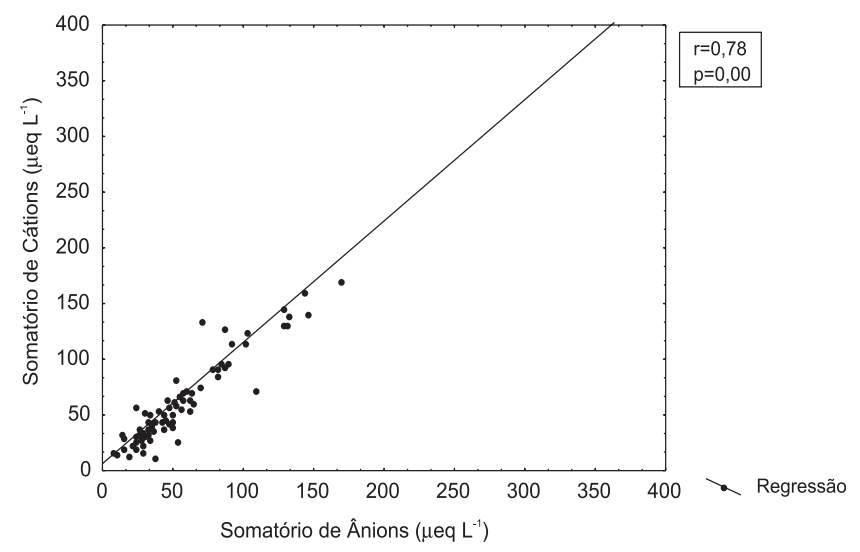

Figura 2. Correlação entre o somatório de cátions e ânions nas amostras de precipitação total

Quanto ao critério que compara a condutividade medida com a calculada, todas as amostras obtiveram uma diferença percentual da condutividade (DPC) $<50 \%$ para uma condutividade medida de até $30 \mu \mathrm{S} \mathrm{cm}^{-1}$, sendo assim este critério não rejeitou nenhuma amostra. A correlação entre a condutividade medida e calculada foi significativa $(\mathrm{r}=0,65, \mathrm{p}=0,00)$ (Figura 3).

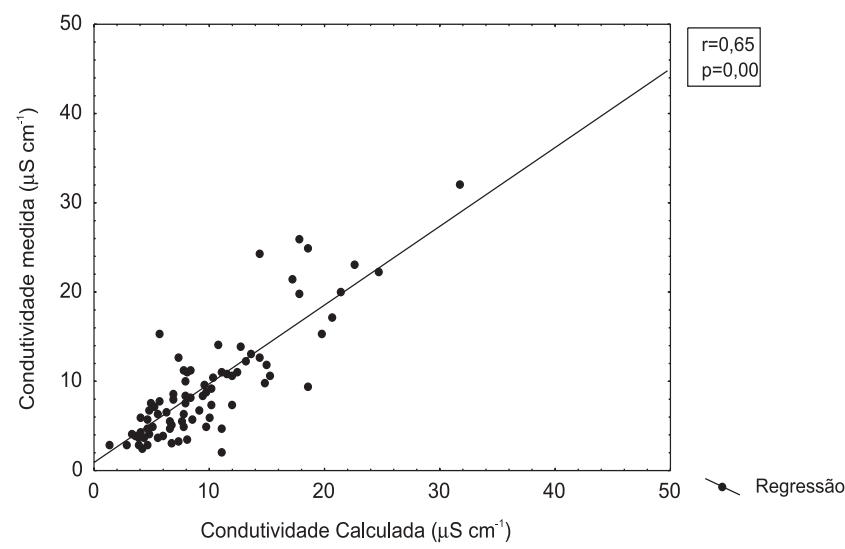

Figura 3. Correlação entre a condutividade medida e calculada nas amostras de precipitação total

Metais

A análise dos metais $\mathrm{Cu}, \mathrm{Zn}, \mathrm{Fe}, \mathrm{Mn}$, e $\mathrm{Al}$ foi realizada pelo método de espectrometria de absorção atômica com forno de gra- 
fite e corretor Zeeman, equipamento Perkin Elmer modelo SIMAA 6000 (Simultaneous Multielement AA Spectrometer). Foram utilizadas soluções padrão certificadas PE-PURE Atomic Spectroscopy Standard (Perkin Elmer). Os limites de detecção foram 1,0 $\mu \mathrm{g} \mathrm{L}^{-1}$ para $\mathrm{Cu}, \mathrm{Fe}$ e $\mathrm{Al} ; 0,5 \mu \mathrm{g} \mathrm{L}^{-1}$ para $\mathrm{Mn}$ e $0,1 \mu \mathrm{g} \mathrm{L} \mathrm{L}^{-1}$ para $\mathrm{Zn}$.

\section{Contribuição marinha e não marinha}

As frações de $\mathrm{Cl}^{-}, \mathrm{SO}_{4}^{2-}, \mathrm{Ca}^{2+}, \mathrm{Mg}^{2+}$ e $\mathrm{K}^{+}$originadas do sal marinho, através da incorporação do "spray" marinho na chuva, normalmente são calculadas utilizando-se a concentração de $\mathrm{Na}^{+}$como íon de referência ${ }^{22,23}$. Esta parcela denominada de concentração em excesso $[X]_{\text {exc }}$ ou $[X]_{n s s}$ ("non sea salts") foi calculada através da seguinte expressão:

$$
[X] \text { exc }=[X]_{\text {amostra }}-\left[\mathrm{Na}^{+}\right]_{\text {amostra }} \cdot \frac{[\mathrm{X}]_{\text {sal marinho }}}{\left[\mathrm{Na}^{+}\right]_{\text {sal marinho }}}
$$

onde $X$ é a concentração do íon em $\mu$ eq $\mathrm{L}^{-1}$.

\section{Tratamento estatístico}

O tratamento estatístico foi aplicado através do software "Statistic for Windows 4,3 $3^{\mathrm{TM}}$ ", a fim de facilitar a interpretação dos resultados. A técnica aplicada foi Análise Fatorial, através do Método dos Componentes Principais.

A Análise Fatorial consiste de uma técnica de Análise Multivariada que trata das relações internas de um conjunto de variáveis, substituindo um conjunto inicial de variáveis correlacionadas por um conjunto menor de "Fatores", que podem, ou não, ser correlacionados, justificando assim a maior parte da variância do conjunto original de dados ${ }^{24}$. Desta forma, é estudada a estrutura de correlação de um conjunto inicial de "p" variáveis $(\mathrm{X} 1, \mathrm{X} 2 \ldots$ $\mathrm{Xp}$ ), substituindo este por um conjunto menor de variáveis hipotéticas, os fatores comuns, com menor número e estrutura mais simples.

Análise Fatorial consiste de três etapas básicas: preparação da matriz de correlação; a extração dos Fatores e a possível rotação de dados para uma solução final à procura de fatores mais simples e interpretáveis ${ }^{25}$.

\section{RESULTADOS E DISCUSSÃO}

\section{Composição química da precipitação atmosférica}

A Tabela 2 mostra os valores de $\mathrm{pH}$, condutividade, alcalinidade e concentrações médias aritméticas e médias ponderadas pelo volume (MPV) dos íons majoritários da precipitação atmosférica (total e úmida) para os locais estudados. A precipitação total foi coletada nas quatro estações de amostragem, enquanto a precipitação apenas úmida somente nas estações Aceguá e 8 de Agosto.

A distribuição da quantidade de precipitação medida para os quatro locais estudados não apresentou variação expressiva: 8 de Agosto com $818 \mathrm{~mm}, 1010 \mathrm{~mm}$ para Aceguá e $847 \mathrm{~mm}$ para Pedras Altas. Na estação do Aeroporto de Bagé a quantidade de precipitação medida foi a mesma registrada na estação Meteorológica do Aeroporto de Bagé (INFRAERO), $901 \mathrm{~mm}$ para o período de janeiro a junho de 2001.

Os valores de $\mathrm{pH}$ na precipitação total mostraram que existe predominância de precipitação levemente ácida na região de Candiota (Figura 4), os resultados mostraram valores de $\mathrm{pH}$ entre 4,1-5,0 e 5,1-5,6 para 14 e 64\% das amostras, respectivamente.

Os resultados de $\mathrm{pH}$ e condutividade foram mais elevados nas

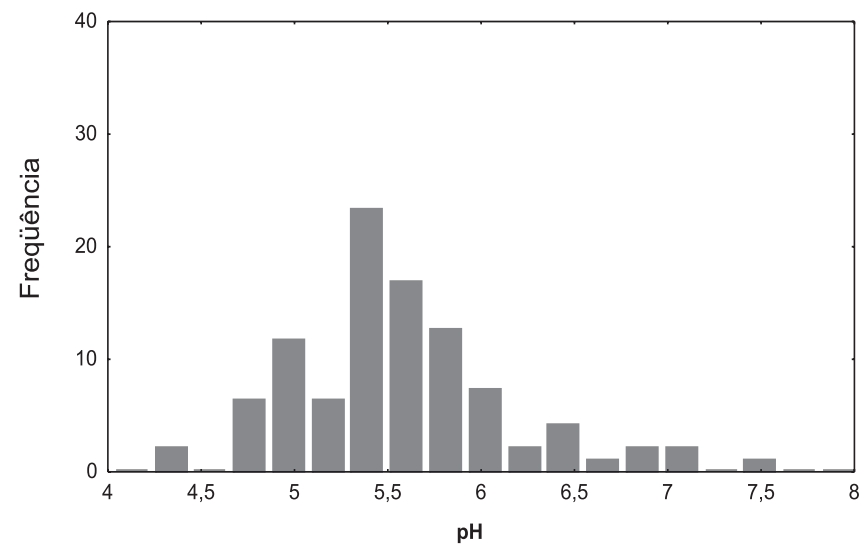

Figura 4. Histograma dos valores de pH na precipitação total, na região de Candiota (valores das quatro estações de amostragem), no período de janeiro a junho de 2001

amostras de precipitação total de Aceguá e 8 de Agosto (Tabela 2). Resultados semelhantes foram encontrados por Aikawa et al. ${ }^{26}$, que verificaram valores de $\mathrm{pH}$ mais elevados nas amostras de precipitação total pela influência da deposição seca nas amostras de precipitação total, provavelmente pelo acúmulo de material particulado no sistema de coleta.

$\mathrm{O}$ valor médio de $\mathrm{pH}$ da região durante o período estudado foi de 5,54 (4,32-7,49), estando na faixa de valores reportados por vários autore $^{27-30}$ para áreas urbanas no Brasil (Porto Alegre, Rio Grande e Niterói) e na Amazônia, embora mais elevados que os reportados por outros autores ${ }^{31}$ para locais como Austrália, Alasca, Venezuela, Sudeste do Brasil ${ }^{32}$ e áreas com influência de termoelétricas a carvão no $\mathrm{Sul}^{33}$.

Outros autores ${ }^{34}$ investigaram a composição da precipitação apenas úmida na fronteira do Brasil-Uruguai (Aceguá-Uruguai), entre 1999 e 2000, e verificaram concentrações de íons majoritários e pH $(5,6)$ mais elevado que os encontrados no presente estudo (Estação Aceguá-Brasil) (Tabela 2). Esta variação pode ser explicada pelos procedimentos distintos empregados nas amostras de precipitação apenas úmida, como amostragem (período, freqüência), filtração (membranas de porosidade diferente) e análise química.

Na precipitação total, os íons que apresentaram concentrações maiores foram $\mathrm{NH}_{4}^{+}, \mathrm{Na}^{+}, \mathrm{Cl}^{-}$e $\mathrm{SO}_{4}^{2-}$ nas quatro estações estudadas. Na estação 8 de Agosto observa-se a maior concentração média de $\mathrm{Ca}^{2+}\left(13,81 \mu\right.$ eq $\left.\mathrm{L}^{-1}\right)$, o que pode ser explicado pela proximidade desta estação com as minas de calcário metamórfico da região (aproximadamente $20 \mathrm{~km}$ a sudoeste).

Comparando os íons majoritários analisados na precipitação total e úmida da região de Candiota, verificaram-se concentrações médias ponderadas mais elevadas nas amostras de precipitação total, exceto para os íons $\mathrm{H}^{+}, \mathrm{Ca}^{2+}, \mathrm{Mg}^{2+}, \mathrm{F}^{-}$e $\mathrm{SO}_{4}^{2-}$ coletados na estação 8 de Agosto. Isto pode ser atribuído ao número de amostras (oito) não ter sido representativo para o período de amostragem, tornando difícil a interpretação dos dados.

A análise da alcalinidade foi realizada somente em $50 \%$ das amostras de precipitação total, não sendo analisada na precipitação úmida pois, para os demais casos, o volume de amostra foi insuficiente para a determinação através do método potenciométrico e/ou para amostras com $\mathrm{pH}$ baixos $(\mathrm{pH} \leq 4,8)$. Os resultados encontrados não foram elevados, isto pode ser explicado pelos valores ácidos de $\mathrm{pH}$ observados nas amostras de precipitação atmosférica (Tabela 2), onde a concentração de carbonato, praticamente, apresenta-se na forma de $\mathrm{HCO}_{3}$.

A Tabela 3 mostra as concentrações médias de Fe, Al, Mn, Zn 
Tabela 2. Composição química e concentração média ponderada pelo volume dos íons $\left(\mu \mathrm{eq}^{-1}\right.$ ) na precipitação total e úmida da região de Candiota, período de janeiro a junho/2001

\begin{tabular}{|c|c|c|c|c|c|c|c|c|c|c|c|c|c|c|}
\hline \multicolumn{15}{|c|}{ Precipitação Total } \\
\hline Estações & & $\mathrm{pH}$ & Cond. & Alc. & $\mathrm{H}^{+}$ & $\mathrm{NH}_{4}^{+}$ & $\mathrm{Ca}^{2+}$ & $\mathrm{Mg}^{2+}$ & $\mathrm{Na}^{+}$ & $\mathrm{K}^{+}$ & $\mathrm{F}^{-}$ & $\mathrm{Cl}^{-}$ & $\mathrm{SO}_{4}{ }^{2-}$ & $\mathrm{NO}_{3}^{-}$ \\
\hline Aceguá & Média & 5,44 & 6,87 & 0,180 & 5,96 & 15,4 & 8,71 & 4,41 & 15,9 & 3,16 & 5,74 & 19,6 & 14,6 & 8,18 \\
\hline \multirow[t]{3}{*}{$24 *$} & MPV & 5,34 & 5,61 & - & 5,21 & 12,8 & 10,1 & 3,07 & 11,4 & 2,84 & 3,88 & 14,2 & 11,7 & 7,82 \\
\hline & Min. & 4,38 & 3,54 & $<$ L.D & 0,38 & $<$ L.D & 2,14 & 0,900 & 1,00 & 0,17 & < L.D & 3,34 & 4,73 & 2,04 \\
\hline & Max. & 6,42 & 15,3 & 0,720 & 41,7 & 41,3 & 33,7 & 22,9 & 97,6 & 13,6 & 52,9 & 116 & 36,9 & 21,7 \\
\hline 8 de Agosto & Média & 5,6 & 8,25 & 0,410 & 3,70 & 18,7 & 13,8 & 5,98 & 15,1 & 4,9 & 3,69 & 18,5 & 17,5 & 11,6 \\
\hline \multirow[t]{3}{*}{$24 *$} & MPV & 5,48 & 5,59 & - & 3,76 & 13,7 & 10,5 & 4,06 & 10,8 & 4,25 & 3,3 & 13,1 & 11,4 & 9,62 \\
\hline & Min. & 4,91 & 2,00 & $<$ L.D & 0,03 & 0,870 & 1,59 & 0,67 & 0,35 & 0,02 & $<$ L.D & 3,27 & 2,93 & 1,12 \\
\hline & Max. & 7,49 & 26,0 & 1,91 & 12,3 & 98,3 & 46,7 & 24,5 & 71,5 & 23,7 & 18,9 & 70,4 & 63,5 & 77,3 \\
\hline Aeroporto de Bagé & Média & 5,81 & 10,1 & 0,600 & 4,75 & 35,4 & 11,9 & 7,08 & 17,7 & 7,78 & 3,14 & 19,2 & 13,2 & 9,87 \\
\hline \multirow[t]{3}{*}{$21 *$} & MPV & 5,58 & 6,30 & - & 3,99 & 18,3 & 69,0 & 4,69 & 13,3 & 6,66 & 3,85 & 14,2 & 10,6 & 7,42 \\
\hline & Min. & 4,32 & 2,45 & $<$ L.D & 0,100 & 0,280 & 3,56 & 0,160 & 0,390 & 0,050 & $<$ L.D & 3,32 & 2,68 & 1,52 \\
\hline & Max. & 7,01 & 32,0 & 2,34 & 47,7 & 226 & 33,0 & 18,0 & 53,5 & 43,1 & 11,7 & 43,3 & 38,0 & 32,5 \\
\hline Pedras Altas & Média & 5,34 & 10,7 & 0,570 & 8,31 & 14,3 & 7,84 & 6,46 & 18,4 & 6,33 & 3,81 & 22,4 & 15,8 & 7,77 \\
\hline \multirow[t]{3}{*}{$25^{*}$} & MPV & 5,44 & 9,07 & - & 7,54 & 13,4 & 7,54 & 5,69 & 15,1 & 7,65 & 3,28 & 18,4 & 14,2 & 6,85 \\
\hline & Min. & 4,66 & 2,80 & $<$ L.D & 0,110 & $<$ L.D & 1,27 & 0,620 & 0,560 & 0,100 & $<$ L.D & $<$ L.D & $<$ L.D & $<$ L.D \\
\hline & Max. & 6,93 & 29,0 & 3,180 & 21,9 & 82,6 & 20,9 & 28,4 & 114 & 42,9 & 12,3 & 137 & 30,9 & 23,1 \\
\hline Região & Média & 5,54 & 8,94 & 0,442 & 5,73 & 20,4 & 10,5 & 5,95 & 16,7 & 5,48 & 4,13 & 20,0 & 15,4 & 9,33 \\
\hline \multirow[t]{3}{*}{ 94* } & MPV & 5,46 & 6,60 & - & 5,12 & 14,5 & $\mathbf{8 , 9 7}$ & 4,33 & 12,6 & 5,27 & 3,60 & 14,9 & 11,9 & 7,90 \\
\hline & Min. & 4,32 & 2,00 & < L.D & $\mathbf{0 , 0 3 2}$ & < L.D & 1,27 & 0,164 & 0,35 & 0,025 & < L.D & < L.D & < L.D & $<$ L.D \\
\hline & Max. & 7,49 & 32,0 & 3,18 & 47,8 & 226 & 46,7 & 28,4 & 114 & 43,1 & 52,9 & 137 & 63,5 & 77,3 \\
\hline \multicolumn{15}{|c|}{ Precipitação Úmida } \\
\hline Aceguá & Média & 5,16 & 6,97 & N. A. & 6,73 & 5,60 & 6,46 & 6,42 & 4,81 & 2,53 & 5,60 & 8,27 & 11,1 & 5,09 \\
\hline \multirow{3}{*}{$19 *$} & MPV & 6,10 & 7,47 & N. A. & 105 & 7,62 & 4,97 & 2,05 & 4,28 & 1,81 & 5,94 & 8,30 & 12,2 & 6,97 \\
\hline & Min. & 4,36 & 3,10 & N. A. & 0,770 & 0,190 & 0,520 & 0,510 & 0,110 & < L.D & < L.D & 1,56 & 2,73 & 1,44 \\
\hline & Max. & 6,11 & 22,5 & N. A. & 22,1 & 16,9 & 26,8 & 83,2 & 27,0 & 25,8 & 41,6 & 32,2 & 37,3 & 11,1 \\
\hline 8 de Agosto & Média & 5,50 & 8,58 & N. A. & 5,39 & 6,73 & 21,2 & 7,91 & 14,4 & 2,98 & 4,20 & 15,4 & 31,2 & 5,32 \\
\hline \multirow{3}{*}{$8 *$} & MPV & 4,51 & 5,22 & N. A. & 4,18 & 3,99 & 12,7 & 4,48 & 6,25 & 1,53 & 2,48 & 6,84 & 16,9 & 3,46 \\
\hline & Min. & 4,54 & 3,25 & N. A. & 0,270 & 0,110 & 3,54 & 2,47 & 1,70 & 0,180 & 0,390 & 2,81 & 4,87 & 0,770 \\
\hline & Max. & 6,56 & 14,8 & N. A. & 8,51 & 11,6 & 31,5 & 8,61 & 11,3 & 5,33 & 7,65 & 12,1 & 38,9 & 9,30 \\
\hline Região & Média & 5,33 & $\mathbf{7 , 7 8}$ & N. A. & 6,06 & 6,17 & 13,8 & 7,17 & 9,61 & 2,76 & 4,9 & 11,8 & 21,2 & 5,21 \\
\hline \multirow[t]{3}{*}{$27 *$} & MPV & 5,31 & 6,35 & N. A. & 54,6 & 5,81 & 8,84 & 3,27 & 5,27 & 1,67 & 4,21 & 7,57 & 14,6 & 5,22 \\
\hline & Min. & 4,36 & 3,10 & N. A. & 0,270 & 0,110 & $\mathbf{0 , 5 2 0}$ & $\mathbf{0 , 5 1 0}$ & 0,110 & < L.D & < L.D & 1,56 & 2,73 & 0,770 \\
\hline & Max. & 6,56 & 22,5 & N. A. & 22,1 & 16,9 & 31,5 & 83,2 & 27 & 25,8 & 41,6 & 32,2 & 38,9 & 11,1 \\
\hline
\end{tabular}

*número de amostras; MPV - Concentração média ponderada pelo volume; L.D - Limite de Detecção; Cond. - Condutividade ( $\mu$ S cm $\left.{ }^{-1}\right)$; Alc. -Acalinidade $\left(\mathrm{mgCaCO}_{3} \mathrm{~L}^{-1}\right)$; N.A. - não analisado

Tabela 3. Concentração média de metais, $\mu \mathrm{g} \mathrm{L}^{-1}$, nas estações de amostragem para a precipitação total da região de Candiota, período de janeiro a março/2001

\begin{tabular}{|c|c|c|c|c|c|c|c|}
\hline \multicolumn{8}{|c|}{ Precipitação Total } \\
\hline Estações & & $\mathrm{Fe}$ & $\mathrm{Mn}$ & $\mathrm{Ni}$ & $\mathrm{Cu}$ & $\mathrm{Zn}$ & $\mathrm{Al}$ \\
\hline \multirow{3}{*}{ Aceguá } & Média & 4,17 & 3,36 & 2,65 & 1,56 & 13,8 & 6,50 \\
\hline & Max. & 13,3 & 6,14 & 3,50 & 2,81 & 19,2 & 14,8 \\
\hline & Min. & 1,10 & 0,570 & 1,80 & 1,09 & 7,40 & 2,88 \\
\hline \multirow{3}{*}{8 de Agosto } & Média & 1,36 & 3,75 & 2,77 & 1,33 & 14,5 & 6,06 \\
\hline & Max. & 1,92 & 12,7 & 3,56 & 1,87 & 26,3 & 9,10 \\
\hline & Min. & 0,63 & 0,52 & 1,34 & 0,60 & 7,90 & 3,01 \\
\hline \multirow{3}{*}{ Aeroporto de Bagé } & Média & 5,69 & 3,33 & 0,580 & 3,77 & 19,5 & 5,71 \\
\hline & Max. & 9,80 & 5,90 & 0,58 & 5,47 & 25,4 & 7,93 \\
\hline & Min. & 1,57 & 1,37 & 0,58 & 0,92 & 9,10 & 1,58 \\
\hline \multirow{3}{*}{ Pedras Altas } & Média & 2,53 & 1,60 & 0,987 & 1,29 & 23,0 & 4,99 \\
\hline & Max. & 5,44 & 5,97 & 1,17 & 2,47 & 41,3 & 7,35 \\
\hline & Min. & 0,960 & 0,520 & 0,740 & 0,710 & 7,51 & 2,07 \\
\hline Região & Média & 3,43 & 3,01 & 1,75 & 1,98 & 17,7 & 5,81 \\
\hline
\end{tabular}


Tabela 4. Taxa média de deposição total e úmida dos íons majoritários ( $\mu$ eq $\mathrm{m}^{-2} \mathrm{~d}^{-1}$ ) nos locais estudados, período de janeiro a junho/ 2001

\begin{tabular}{|c|c|c|c|c|c|c|c|c|}
\hline & \multicolumn{5}{|c|}{ Deposição Total } & \multicolumn{3}{|c|}{ Deposição Úmida } \\
\hline & Aceguá & $\begin{array}{c}8 \mathrm{de} \\
\text { Agosto }\end{array}$ & $\begin{array}{c}\text { Aeroporto } \\
\text { de Bagé }\end{array}$ & $\begin{array}{c}\text { Pedras } \\
\text { Altas }\end{array}$ & $\begin{array}{l}\text { Região } \\
\text { Candiota }\end{array}$ & Aceguá & $\begin{array}{c}8 \mathrm{de} \\
\text { Agosto }\end{array}$ & $\begin{array}{l}\text { Região } \\
\text { Candiota }\end{array}$ \\
\hline$\overline{\mathrm{H}^{+}}$ & 105 & 72,8 & 108 & 129 & 104 & 118 & 84,5 & 101 \\
\hline $\mathrm{HCO}_{3}^{-}$ & 44,9 & 66,1 & 94,5 & 31,6 & 57,9 & 3,71 & 7,06 & 5,39 \\
\hline $\mathrm{NH}_{4}^{+}$ & 228 & 198 & 322 & 143 & 219 & 54,7 & 89,9 & 72,3 \\
\hline $\mathrm{Ca}^{2+}$ & 159 & 124 & 132 & 78,0 & 123 & 34,2 & 194 & 114 \\
\hline $\mathrm{Mg}^{2+}$ & 62,6 & 51,5 & 64,3 & 57,1 & 58,7 & 138 & 76,3 & 107 \\
\hline $\mathrm{Na}^{+}$ & 228 & 161 & 234 & 145 & 190 & 37,5 & 121 & 79,3 \\
\hline $\mathrm{K}^{+}$ & 38,6 & 62,0 & 127 & 67,1 & 72,0 & 44,7 & 24,0 & 34,4 \\
\hline $\mathrm{F}^{-}$ & 52,0 & 54,7 & 77,4 & 65,8 & 62,0 & 47,4 & 55,8 & 51,6 \\
\hline $\mathrm{Cl}^{-}$ & 288 & 215 & 261 & 178 & 234 & 67,5 & 138 & 103 \\
\hline $\mathrm{SO}_{4}^{2-}$ & 196 & 181 & 223 & 183 & 195 & 85,1 & 319 & 202 \\
\hline $\mathrm{NO}_{3}^{-}$ & 117 & 133 & 132 & 92,6 & 118 & 42,3 & 69,9 & 56,1 \\
\hline
\end{tabular}

e $\mathrm{Cu}$ nas quatro estações de amostragem para o período de janeiro a março/2001. Zn foi o elemento que apresentou maior concentração média ponderada de $17,7 \mu g \mathrm{~L}^{-1}(7,40$ - 41,3). As elevadas concentrações de $\mathrm{Zn}$ podem estar relacionadas à emissão deste elemento proveniente da Usina Termoelétrica Presidente Médici, pois estudos $^{35}$ estimaram em 72 t por ano de $\mathrm{Zn}$, sendo aproximadamente 20 vezes mais elevado que em termométricas da Holanda e Estados Unidos ${ }^{36}$.

Al apresentou concentração média de 5,81 $\mu \mathrm{g} \mathrm{\textrm {L } ^ { - 1 }}$ com valor máximo na estação Aceguá $\left(14,8 \mu \mathrm{g} \mathrm{L}^{-1}\right)$. Nesta estação o Fe apresentou também concentração máxima de $13,3 \mu \mathrm{g} \mathrm{\textrm {L } ^ { - 1 }}$. De forma genérica, esses metais estudados apresentaram concentrações menores em amostras de precipitação atmosféricas que os encontrados na Alemanha, Rússia e Itália ${ }^{37-39}$.

\section{Taxa de deposição}

A Tabela 4 mostra as taxas médias de deposição total e úmida dos íons majoritários para os locais estudados. Os resultados evidenciaram maiores taxas médias de deposição total no solo na região de Candiota, para os íons $\mathrm{NH}_{4}^{+}\left(219 \mu e q \mathrm{~m}^{-2} \mathrm{~d}^{-1}\right), \mathrm{Na}^{+}$ $\left(190 \mu e q \mathrm{~m}^{-2} \mathrm{~d}^{-1}\right), \mathrm{Cl}^{-}\left(234 \mu e q \mathrm{~m}^{-2} \mathrm{~d}^{-1}\right) \mathrm{e} \mathrm{SO}_{4}^{2-}\left(195 \mu e q \mathrm{~m}^{-2} \mathrm{~d}^{-1}\right)$.

A deposição média mais elevada de $\mathrm{NH}_{4}^{+}$verificada, em Aceguá e Aeroporto de Bagé, pode estar relacionada às atividades agropecuárias, principalmente criação de gado, também reportado por outros estudos ${ }^{34}$. A taxa de $\mathrm{SO}_{4}{ }^{2-}$ apresentou-se entre os valores encontrados em áreas remotas e poluídas do Hemisfério Norte, principalmente no nordeste da Espanha, área com influência de usina termoelétrica a carvão, semelhante à região de Candiota. E os valores de $\mathrm{Ca}^{2+}$ estão de acordo com os encontrados em uma área de mineração de calcário na Espanha ${ }^{40}$.

Destacam-se nas estações de Aceguá, Aeroporto de Bagé e 8 de Agosto taxa de deposição total para $\mathrm{Ca}^{2+}$ de 160,132 e $124 \mu e q \mathrm{~m}^{-2} \mathrm{~d}^{-1}$, respectivamente. A presença de $\mathrm{Ca}^{2+}$ na atmosfera deve-se a mineração de calcário na região, e pode ser removido através da precipitação na forma de $\mathrm{CaCO}_{3}$, ou reagir com espécies ácidas $\left(\mathrm{SO}_{2}, \mathrm{NO}_{x}, \mathrm{H}_{2} \mathrm{SO}_{4}\right.$ e $\left.\mathrm{HNO}_{3}\right)$ e formar sais de sulfato e nitrato $^{41}$.

\section{Contribuição marinha}

A Tabela 5 mostra o percentual da concentração em excesso (exc) dos íons $\mathrm{Ca}^{2+}, \mathrm{Mg}^{2+}, \mathrm{K}^{+}, \mathrm{Cl}^{-}$e $\mathrm{SO}_{4}{ }^{2-}$ nas amostras de precipitação total e úmida para cada estação de amostragem. Verifica-se a
Tabela 5. Percentual da concentração em excesso (exc) das amostras de precipitação total e úmida na região de Candiota, período de janeiro a junho/2001

\begin{tabular}{lccccc}
\hline \multicolumn{7}{c}{ Precipitação Total } \\
\hline $\mathrm{Ca}^{2+}$ & $\mathrm{Mg}^{2+}$ & $\mathrm{K}^{-}$ & $\mathrm{Cl}^{-}$ & $\mathrm{SO}_{4}^{2-}$ \\
\hline 8 de Agosto & 96 & 50 & 94 & 14 & 90 \\
Aceguá & 93 & 25 & 91 & 17 & 87 \\
Aeroporto de Bagé & 94 & 50 & 96 & 12 & 84 \\
Pedras Altas & 91 & 35 & 94 & 10 & 82 \\
\hline Região de Candiota & 94 & 40 & 94 & 13 & 86 \\
\hline & Precipitação Úmida & & & \\
\hline 8 de Agosto & 97 & 50 & 90 & 2 & 94 \\
Aceguá & 97 & 57 & 92 & 37 & 95 \\
\hline Região de Candiota & 97 & 52 & 91 & 22 & 95 \\
\hline
\end{tabular}

presença de contribuição do spray marinho para os íons $\mathrm{Mg}^{2+}$ e $\mathrm{Cl}^{-}$, cujos valores não ultrapassaram $52 \%$ da concentração em excesso (exc), para todas as estações. Entretanto, os íons $\mathrm{Ca}^{2+}$ exc, $\mathrm{K}^{+}$exc e $\mathrm{SO}_{4}^{2-}$ exc apresentaram um percentual superior a $80 \%$, revelando uma origem antropogênica/continental destes íons.

Nas amostras de precipitação úmida, o comportamento do percentual da concentração em excesso (exc) foi similar para as duas estações estudadas (Aceguá e 8 de Agosto), exceto na estação Aceguá, cujo percentual de $\mathrm{Cl}^{-}$exc foi de $37 \%$.

De acordo com os resultados obtidos no presente estudo, estima-se que cerca de $86 \%$ do sulfato presente nas amostras de precipitação total e $95 \%$ na precipitação úmida sejam originários da concentração em excesso de $\mathrm{SO}_{4}{ }^{2-}\left(\mathrm{SO}_{4}{ }^{2-}\right.$ exc $)$. No entanto, não é possível distinguir entre sulfato originário do processo de fotooxidação dos gases de enxofre de origem biológica e aquele produzido diretamente pela queima de combustíveis fósseis. Entretanto, sugere-se que a contribuição do sulfato seja proveniente da usina (UPME), sendo esta a fonte mais significativa para as emissões antropogênicas de SOx da região de Candiota.

$\mathrm{O}$ percentual da concentração em excesso para os íons $\mathrm{K}^{+} \mathrm{e}$ $\mathrm{Ca}^{2+}$ foi semelhante para as amostras de precipitação total e úmida, com valores em torno de $95 \%$ (Tabela 5). Este percentual pode sugerir uma origem do solo, principalmente para o $\mathrm{Ca}^{2+}$, devido à ocorrência de mineração e extração de calcário na região de estu$\mathrm{do}^{42}$. 
A presença de $\mathrm{Cl}^{-}$exc nas amostras de precipitação atmosféricas do presente estudo aproximou-se da fração molar reportada por Keene et al. ${ }^{22}$ para sal marinho $(1,17)$, a partir destes resultados optou-se por considerar como única fonte de $\mathrm{Na}^{+}$a brisa marinha. Os resultados de $\mathrm{Cl}^{\prime}$ exc indicaram que 8 e $22 \%$ dos eventos de precipitação total e úmida, respectivamente, são atribuídos à origem antropogênica/continental na precipitação atmosférica da região estudada; provavelmente, este percentual esteja relacionado à emissão da Usina (UPME). Estudo realizado em amostras de carvão queimadas na usina termoelétrica (UPME) estimou que a emissão de cloreto para a atmosfera pode ser de aproximadamente 192 t ano ${ }^{-1}{ }^{43}$. Entretanto, a contribuição marinha deste íon pode ser explicada pela circulação atmosférica de mesoescala ocorrida na região, apesar desta localizar-se a uma distância superior a 100 km do oceano sofre, mesmo assim, influência da brisa marinha ${ }^{49}$.

A concentração em excesso de $\mathrm{Cl}^{-}$exc apresentou-se menos significativa na estação Pedras Altas (10\%), seguida do Aeroporto de Bagé (12\%). Isto pode estar relacionado à circulação da brisa marinha na região; quando esta provém da direção predominante do vento da região (nordeste), e encontra o sistema frontal (formação de chuva), proveniente da direção noroeste (mais freqüente), ocorre um bloqueio significativo do escoamento do vento causado pela topografia provocando, assim, a deposição dos íons, principalmente $\mathrm{Na}^{+}$e $\mathrm{Cl}^{-}$, na estação Pedras Altas, que está localizada a uma altitude de aproximadamente $420 \mathrm{~m}$.

Com base nas considerações acima, pode-se observar que as concentrações em excesso (exc) dos íons analisados foram mais significativas para os $\mathrm{SO}_{4}^{2-}, \mathrm{Ca}^{2+}$ e $\mathrm{K}^{+}$em todas as estações estudadas. Este comportamento pode sugerir a provável origem antropogênica destes íons na região, $\mathrm{SO}_{4}{ }^{2-}$ proveniente da queima de carvão para a geração de energia elétrica, $\mathrm{Ca}^{2+}$ pela influência das minas de calcário e $\mathrm{K}^{+}$pela queima da biomassa, atividade muito freqüente na região em estudo. Como esperado, as concentrações de origem marinha foram verificadas para os íons $\mathrm{Cl}^{-}$e $\mathrm{Mg}^{2+}$, também reportados em outros estudos ${ }^{34,44,45}$.

\section{Tratamento estatístico}

A análise estatística foi aplicada às amostras de precipitação total (94 amostras), a fim de facilitar a interpretação dos dados obtidos. A partir da análise descritiva das variáveis estudadas obteve-se média, mínimo e máximo, anteriormente citada na Tabela 2. Foram excluídos da análise estatística $\mathrm{H}^{+}, \mathrm{F}^{-}$e alcalinidade, por não apresentarem correlação significativa ( $p>0,01,99 \%$ de significância), totalizando assim 8 variáveis para aplicação da Análise Fatorial.

A partir da matriz de correlação, foram obtidos dois novos conjuntos de variáveis sintéticas (Fatores Comuns), baseados nas interrelações dos dados originais. Estes Fatores, associados às raízes características $>1,0$, explicaram $66,8 \%$ da variância total. Para uma melhor distribuição dos fatores foi aplicada a rotação varimax, que resultou em cargas fatoriais de 37,5 e 29,3\% Fator 1 e Fator 2, respectivamente.

Na Tabela 6 observam-se as cargas fatoriais para as variáveis selecionadas, sendo que o Fator 1 representa 37,5\% da variância total em relação aos dados brutos. Este Fator, interpretado como altamente ponderado, com pesos $>0,5$, é representado pelas variáveis $\mathrm{Mg}^{2+}, \mathrm{Na}^{+}$e $\mathrm{Cl}^{-}$, indicando uma influência da brisa marinha na região estudada. Essa influência foi verificada na direção sudeste em relação à fonte emissora, cujos dados estão de acordo com os encontrados no presente estudo.

Estudo realizado em Aceguá (Uruguai) indicou também ori-

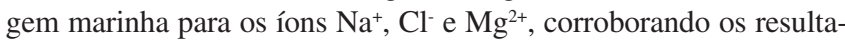
dos obtidos do presente estudo ${ }^{32}$.
Tabela 6. Matriz de cargas fatoriais obtida, após rotação varimax, para as amostras de precipitação total na região de Candiota, no período de janeiro a junho/2001

\begin{tabular}{lcc}
\hline Variáveis & Fator 1 & Fator 2 \\
\hline $\mathrm{NH}_{4}^{+}$ & 0,0152 & $\mathbf{0 , 8 2 4}$ \\
$\mathrm{Ca}^{2+}$ & 0,398 & $\mathbf{0 , 5 8 0}$ \\
$\mathrm{Mg}^{2+}$ & $\mathbf{0 , 8 0 7}$ & 0,356 \\
$\mathrm{Na}^{+}$ & $\mathbf{0 , 9 5 4}$ & 0,0860 \\
$\mathrm{~K}^{+}$ & 0,234 & $\mathbf{0 , 6 9 3}$ \\
$\mathrm{Cl}^{-}$ & $\mathbf{0 , 9 6 6}$ & 0,001 \\
$\mathrm{SO}_{4}^{2-}$ & 0,429 & 0,534 \\
$\mathrm{NO}_{3}^{-}$ & $-0,0352$ & $\mathbf{0 , 6 5 1}$ \\
\hline Variância Total \% & $\mathbf{3 7 , 5}$ & $\mathbf{2 9 , 3}$ \\
\hline
\end{tabular}

Valores em negrito cargas fatoriais $>0,500$

No Fator 2, a variância total é explicada por 29,3\% dos dados brutos, sendo representados por $\mathrm{NH}_{4}^{+}, \mathrm{Ca}^{2+}, \mathrm{K}^{+}, \mathrm{SO}_{4}^{2-}$ e $\mathrm{NO}_{3}^{-}$, evidenciando a provável influência das fontes antropogênicas existentes na região.

A região de Candiota é uma área rural, onde cerca de $90 \%$ da área é ocupada com pastagens, o que revela o desenvolvimento da pecuária extensiva e, também, o cultivo de lavouras temporárias, como ervilha, cevada e sorgo em grão, representando cerca de $30,79 \%$ do total do estado do Rio Grande do $\mathrm{Sul}^{46}$.

Desta forma a associação dos íons $\mathrm{NH}_{4}^{+} \mathrm{e} \mathrm{K}^{+}$pode indicar a queima da biomassa e, além disso, deve-se considerar a contribuição de $\mathrm{NH}_{4}{ }^{+}$proveniente dos dejetos humano e animal e do uso como fertilizante na agricultura ${ }^{32,47}$.

Certos compostos quando formados na precipitação, tais como, $\left(\mathrm{NH}_{4}\right)_{2} \mathrm{SO}_{4},\left(\mathrm{NH}_{4}\right) \mathrm{HSO}_{4}, \mathrm{NH}_{4} \mathrm{NO}_{3}, \mathrm{CaSO}_{4}$ e $\mathrm{Ca}\left(\mathrm{NO}_{3}\right)_{2}$ podem sugerir a presença dos íons $\mathrm{SO}_{4}^{2-}, \mathrm{Ca}^{2+}, \mathrm{NH}_{4}^{+}$e $\mathrm{NO}_{3}^{-}$no Fator $2^{44,48}$.

As Figuras 5 a 8 mostram a distribuição temporal e espacial dos Fatores 1 e 2 para as quatro estações estudadas na região de Candiota.

A Figura 5 apresenta a distribuição dos Fatores 1 e 2 da estação Aceguá, onde foram verificados escores mais elevados no Fator 1 $\left(\mathrm{Mg}^{2+}, \mathrm{Cl}^{-}\right.$e $\left.\mathrm{Na}^{+}\right)$no dia 29/04 (3,89) indicando uma influência de sais marinhos neste evento. Já para o Fator 2, representado por $\mathrm{SO}_{4}{ }^{2-}, \mathrm{Ca}^{2+}, \mathrm{NH}_{4}^{+}$e $\mathrm{NO}_{3}^{-}$o escore mais elevado foi observado no dia

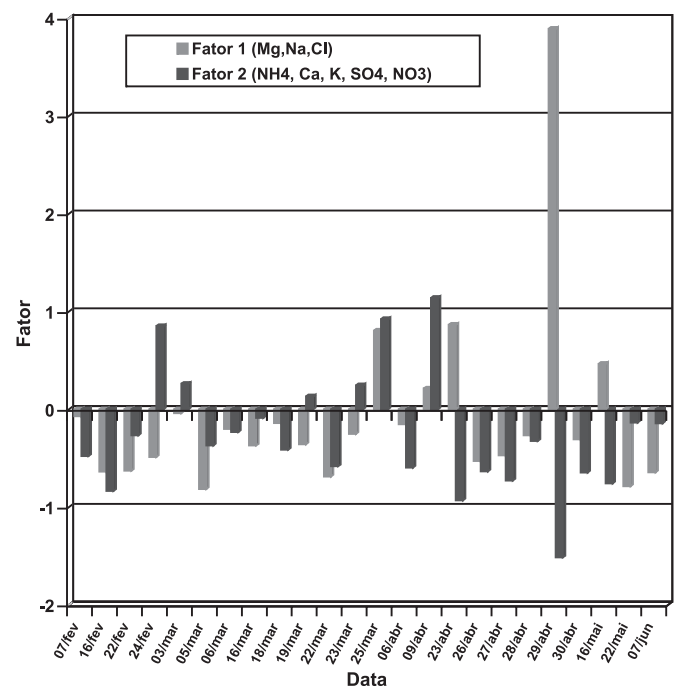

Figura 5. Variação espacial e temporal do Fator 1 e 2 na precipitação total - Estação Aceguá - da região de Candiota, RS 
09/04 $(1,14)$, podendo ser atribuído à direção do vento neste dia ser de nordeste em relação à fonte emissora (UPME). Nesta direção a pluma pode percorrer alguns quilômetros até ser depositada no solo, devido à influência da topografia plana na região ${ }^{49}$.

A distribuição dos escores dos Fatores 1 e 2 para a estação 8 de Agosto é mostrada na Figura 6, verificando escores do Fator 2 mais elevados nos meses de janeiro, fevereiro e março. Nos dias 16/03 $(1,53)$ e $22 / 05(3,21)$ foram observados os maiores escores, estando atribuídos ao $\mathrm{SO}_{4}^{2-}$, sendo registradas as maiores concentrações ponderadas de $\mathrm{SO}_{4}^{2-}\left(63,5 \mu\right.$ eq $\left.\mathrm{L}^{-1}\right)$.

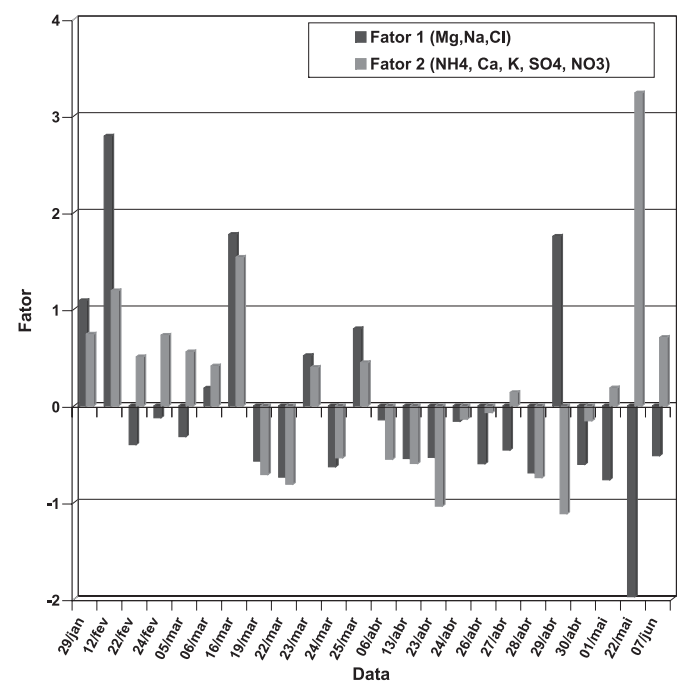

Figura 6. Variação espacial e temporal do Fator 1 e 2 na precipitação total - Estação 8 de Agosto - da região de Candiota, $R S$

Convém ressaltar que estes dados estão associados à direção do vento sudeste, contrariando de certa forma a direção preferencial de nordeste da fonte emissora em relação à fonte receptora ( 8 de Agosto). Estes resultados podem estar relacionados à baixa precipitação verificada na estação meteorológica do Aeroporto de Bagé (90 mm), ocasionado assim uma concentração mais elevada para certos íons, como no caso o $\mathrm{SO}_{4}{ }^{2-}$.

Os escores fatoriais da estação Aeroporto de Bagé são apresentados na Figura 7. O escore mais elevado do Fator 1 foi verificado no dia 29/01 (1,21), cuja direção predominante do vento era sudes-

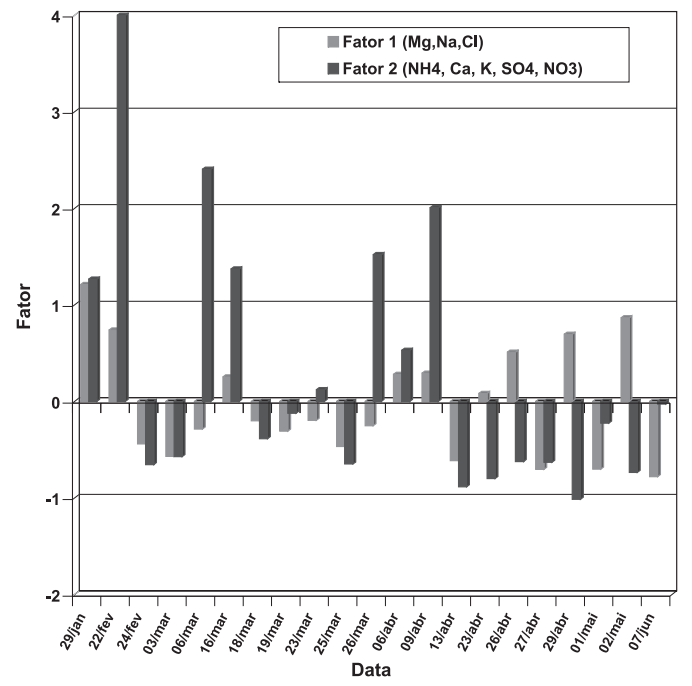

Figura 7. Variação espacial e temporal do Fator 1 e 2 na precipitação total -Estação Aeroporto de Bagé - da região de Candiota, RS te em relação à fonte emissora. O Fator 2 mostrou escores mais elevados nos meses de janeiro, fevereiro, março e abril. No dia 22/ 02 o escore mais elevado $(4,51)$ foi ocasionado pela presença das maiores concentrações de $\mathrm{NH}_{4}^{+}\left(227 \mu \mathrm{eq} \mathrm{L}{ }^{-1}\right)$ e $\mathrm{SO}_{4}^{2-}\left(38,0 \mu \mathrm{eq} \mathrm{L}{ }^{-1}\right)$. Neste caso, a direção predominante do vento em relação à fonte emissora era noroeste. Este fato ocorreu, também, para o dia 09/04 $(2,00)$ caracterizando, provavelmente, emissões oriundas da área urbana da cidade de Bagé.

Para a estação Pedras Altas (Figura 8), observa-se escores mais elevados no Fator 1 para os dias 12/01(3,20), 24/02(4,79) e 26/ 03(1,67), associado à direção do quadrante leste/sul da fonte emissora. O Fator 2 apresenta escores mais elevados nos dias 26/03 (2,34) e 06/06 (2,37), com direções predominantes do quadrante leste/sul e norte/leste, respectivamente, em relação à fonte emissora.

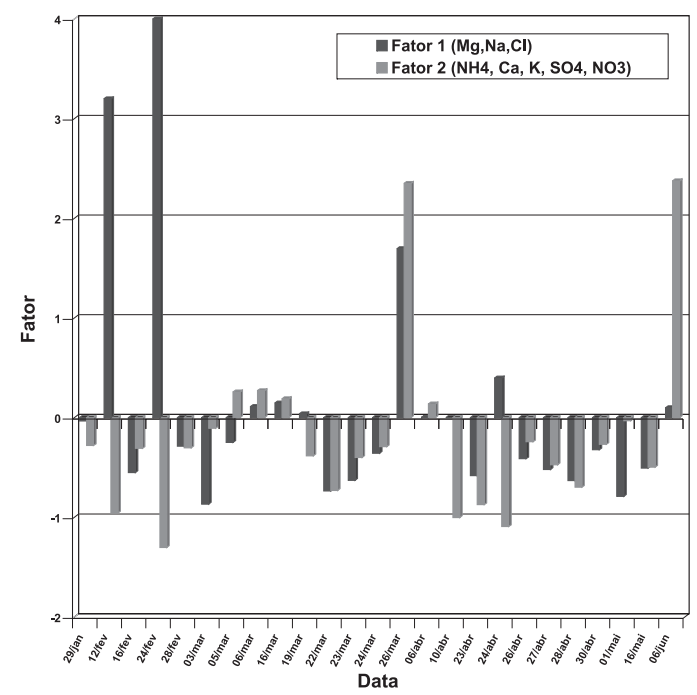

Figura 8. Variação espacial e temporal do Fator 1 e 2 na precipitação total - Estação Pedras Altas - da região de Candiota, RS

A Análise Fatorial permitiu identificar a influência das fontes naturais e antropogênicas na precipitação total da região estudada, possibilitando uma melhor interpretação e avaliação das inter-relações do conjunto de variáveis químicas e físico-químicas com a direção predominante do vento para cada evento estudado. Observou-se, ainda, que os escores fatoriais mais elevados, para os quatro locais, foram caracterizados pelas máximas concentrações ponderadas dos íons analisados no presente estudo.

\section{CONCLUSÃO}

Os resultados de $\mathrm{pH}$ da precipitação atmosférica na região de Candiota revelaram a ocorrência de precipitação levemente ácida, onde $42 \%$ das amostras de precipitação atmosférica analisadas apresentaram $\mathrm{pH}$ entre 4,0 e 5,6. Dentre as quatro estações estudadas, a estação Pedras Altas foi a que apresentou maior percentual de acidez. Os valores de $\mathrm{pH}$ da precipitação úmida apresentaramse mais ácidos que os da precipitação total; isto pode estar relacionado à presença de material particulado contendo carbonatos e hidróxidos, que se acumulam no sistema de coleta do amostrador total, ocasionando neutralização da acidez das amostras.

Os resultados dos íons majoritários estudados evidenciaram concentrações médias ponderadas mais elevadas, nos quatro locais estudados, para $\mathrm{NH}_{4}^{+}, \mathrm{Na}^{+}, \mathrm{Cl}^{-}$e $\mathrm{SO}_{4}^{2-}$.

Os íons $\mathrm{NH}_{4}^{+}, \mathrm{Na}^{+}, \mathrm{Cl}^{-}$e $\mathrm{SO}_{4}{ }^{2-}$ apresentaram maior taxa de deposição total na região indicando influência antropogênica de $\mathrm{NH}_{4}^{+}$ 
e $\mathrm{SO}_{4}^{2-}$, enquanto que $\mathrm{Na}^{+}$e $\mathrm{Cl}^{-}$, contribuição de sais marinhos na precipitação atmosférica da região estudada.

O uso da técnica da Análise Fatorial, aplicada às concentrações dos íons majoritários, facilitou a interpretação dos resultados, possibilitando a correlação com as direções predominantes do vento de cada evento estudado.

Desta forma, foi possível observar a contribuição de sais marinhos e de fontes antropogênicas na área estudada. Os resultados revelaram o agrupamento das variáveis $\mathrm{Na}^{+}, \mathrm{Cl}^{-}$e $\mathrm{Mg}^{2+}$ em um único fator (Fator 1) indicando a possível contribuição de sais marinhos na precipitação atmosférica. Entretanto, os demais íons $\mathrm{NH}_{4}^{+}$, $\mathrm{Ca}^{2+}, \mathrm{K}^{+}, \mathrm{SO}_{4}{ }^{2-} \mathrm{e} \mathrm{NO}_{3}^{-}$, agrupados em outro fator (Fator 2), evidenciaram as principais fontes antropogênicas da região, tais como a influência da termoelétrica, da queima da biomassa e da agricultura na região, salientada nas estações 8 de Agosto e Aeroporto de Bagé, e uma menor contribuição na estação Pedras Altas.

\section{AGRADECIMENTOS}

Ao PADCT/CIAMB, ao CNPq e à Fundação de Amparo à Pesquisa do Estado do Rio Grande do Sul (FAPERGS) pelo suporte financeiro, ao Serviço de Amostragem da Fundação Estadual de Proteção Ambiental Henrique Luís Roessler/RS (FEPAM) e à Companhia de Geração Térmica de Energia Elétrica (CGTEE) pela sua contribuição neste estudo.

\section{REFERÊNCIAS}

1. Overrein, L. N.; Water Sci. Technol. 1983, 19, 1.

2. Mc Cormick, J.; Acid Earth: The Politics of Acid Pollution, $3^{\text {rd }}$ ed., London, 1997.

3. Wellburn, A.; Air pollution and acid rain: the biological impact, New York, 1988.

4. Rosa, A. R.; Migliavacca, D. M.; Teixeira, E. T.; Porto, F. N. M.; $3^{\text {rd }}$ International Symposium Environmental Geochemistry in Tropical Countries, Nova Friburgo, Brasil, 1999.

5. Sánchez, J. D.; Teixeira, E. C.; Fernandes, I. D.; $4^{\text {th }}$ International Symposium on Environmental Issues and Waste Management in Energy and Mineral Production, Caligari, Italy, 1996.

6. Fiedler, H. D.; Dissertação de Mestrado, Universidade Federal do Rio Grande do Sul, Brasil, 1987.

7. Moraes, O. L. L.; Tirabassi, T.; Alves, R. C. M.; Air Pollution 1997, 4, 35; Moraes, O. L. L.; Oliveira, A. P.; Caetano Neto, E. S.; Degrazia, G.; Workshop on Air Pollution and Acid Rain the Candiota Program, Bauru, Brasil, 1996.

8. Braga, C. F.; Alves, R. C. M.; Teixeira, E. C.; Pires, M.; J. Environ. Monit. 2002, 4, 897 .

9. Migliavacca, D. M.; Dissertação de Mestrado, Pontifícia Universidade Católica do Rio Grande do Sul, Brasil, 2001.

10. PADCT/CIAMB; Relatório Parcial. Estudo da contaminação aquática e atmosférica em áreas que sofrem influência das atividades do processamento de carvão - região de Candiota - RS, 1998.

11. Braga, C. F.; Alves, R. C. M.; Teixeira, E. C.; Pires, M.; J. Environ. Monit. 2002, 4, 897 .

12. COPELMI/HAIR; Estudos de Impacto ambiental / Relatório de Impacto Ambiental, 2000

13. FEPAM - FUNDAÇÃO ESTADUAL DE PROTEÇÃO AMBIENTAL; Relatório Interno. Índice de acidez dos corpos hídricos na região de influência de Candiota, 1992.

14. DNM - Departamento Nacional de Meteorologia (Brasil), 1992, p. 84.
15. ASTM; Standard guide for choosing locations and sampling methods to monitor atmospheric deposition at non-urban locations: D 5111, West Conshohocken, PA, 1996.

16. Fornaro, A.; Isolani, P. C.; Gutz, I. G. R.; Atmos. Environ. 1993, 27, 307.

17. ASTM; Standard guide for preparation of material used for the collection and preservation of atmospheric wet deposition: D 5012, West Conshohocken, PA, 1996.

18. APHA; AWWA; WEF; Standard methods for the examination of water and waste waster, 18 ed., Washington, 1992.

19. Barrionuevo, S.; Nascimento, R. S. H.; Machado, A. C. M.; Pires, M.; Estudos ambientais em Candiota: carvão e seus impactos, ed. FINEP/ PADCT/CIAMB/FABERGS/FEPAM, Porto Alegre, 2003, cap. 5.1.

20. Campos, V. P.; Costa, A. C.; Tavares, T. M.; Quim. Nova 1998, 21, 418.

21. Mosello, R.; Bianchi, M.; Geiss, H.; Marchetto, A.; Serrini, G.; Serrini Lanza, G.; Tartari, G. A.; Muntau, H.; AQUACON-MedBas PROJECT Subproject $n^{\circ}$ 6: Acid rain analysis, Luxembourg, 47, 1997.

22. Keene, W. C.; Pszenny, A. A. P.; Galloway, J. N.; Hawley, M. E.; J. Geophys. Res. 1986, 91, 6647.

23. Mello, W. Z.; Ciência e Cultura 1988, 40, 1008.

24. Fachel, J. M. G.; Tese de Doutorado, Universidade de São Paulo, Brasil, 1976.

25. Hair, J. R.; Anderson, R. E.; Tatham, R. L.; Back, W. C.; Multivariate Data Analysis, $5^{\text {th }}$ ed., Prentice-Hall: New Jersey, 1998.

26. Aikawa, M.; Hiraki, T.; Tamaki, M.; Mitsuru, S.; Atmos. Environ. 2003, 37, 2597.

27. Milano, L. B. M.; Luca, S. J.; Rosauro, N. M. L.; Castro, C. M. B.; Revista Brasileira de Engenharia, Caderno de Recursos Hídricos 1989, 7, 39.

28. Mirlean, N.; Vanz, A.; Baisch, P.; Quim. Nova 2000, 23, 590.

29. Mello, W. Z.; Motta, J. S. T.; Ciência Hoje 1987, 6, 40.

30. Williams, E. J.; Fisher, T. R.; Melack, J. M.; Atmos. Environ. 1997, 31, 207.

31. Galloway, J. N.; Linkens, G. E; Keene, W. C.; Miller, J. M.; J. Geophys. Res. 1982, 87, 8771.

32. Lara, L. B. L. S.; Artaxo, P.; Martinelli, L. A.; Victoria, R. L.; Camargo, P. B.; Krusche, A.; Ayers, G. P.; Ferraz, E. S. B.; Ballester, M. V.; Atmos. Environ. 2001, 35, 4937.

33. Flues, M.; Hamma, P.; Lemes, M. J. L; Dantas, E. S. K; Fornaro, A.; Atmos. Environ. 2002, 36, 2397.

34. Zunckel, M.; Saizar, C.; Zarauz, J.; Atmos. Environ. 2003, 37, 1601.

35. Zanella, R. ; Dissertação de Mestrado, Universidade Federal de Santa Maria, Brasil, 1987.

36. Pires, M. J. R. Meio Ambiente e carvão, eds. FINEP/PADCT-GTM/ CAPES/ PUCRS/ UFSM/ FEPAM, Porto Alegre, 2002, p. 275.

37. Hofmann, H.; Hoffmann, P.; Lieser, K. H.; Fresenius J. Anal. Chem. 1991, $340,591$.

38. Hoffmann, H.; Karandashev, A.; Sinner, T.; Fresenius J. Anal. Chem. 1997, $357,1142$.

39. Argese, E.; Giurin, G.; Orsega, E. F.; Zonta, R. V.; Finotti, F.; Gottardi, C.; $10^{\text {th }}$ International Conference on Heavy Metals in the Environment, Edinburgh, Reino Unido, 1995.

40. Alastuery, A.; Querol, X.; Aura Chaves, C. R.; Carratala, A.; Lopez-Soler, A.; Environ. Pollut. 1999, 106, 359.

41. Winchester, J. W.; Wang, M.; Tellus. 1989, 41B, 323.

42. Streck, C. D.; Dissertação de Mestrado, Pontifícia Universidade Católica do Rio Grande do Sul, Brasil, 2001.

43. Fernandes, I. D.; Sanchez, J. D. C.; Teixeira, E. C.; Pankowinsk, A.; Moreira, L. S.; $4^{\text {th }}$ International Symposium on Environmental Issues and Waste Management in Energy and Mineral Production, Caligari, Italy, 1996.

44. Lee, B. K.; Hong, S. H.; Lee, D. S.; Atmos. Environ. 2000, 34, 563.

45. Mello, W. Z.; Environ. Pollut. 2001,114, 235.

46. Fritz, K. B. B.; Impactos sócio-econômicos do uso do carvão mineral, EdiFAPES, Erechim, Brasil, 2001.

47. Saxena, A.; Kulshrestha, U. C.; Kumar, N.; Kumari, K. M.; Srivastava, S. S.; Atmos. Environ. 1996, 30, 3405.

48. Kawaja, H. A.; Husain, L.; Atmos. Environ. 1990, 24, 1869.

49. Alves, R. C. M.; Tese de Doutorado, Universidade de São Paulo, Brasil, 2000 . 